\title{
Effects of Boron Applications on Flower Spike Dieback of Statice (Limonium spp.)
}

\author{
Chang-Hak Choi, Dong-Chun Jeong, Jin-Jae Lee, Young-Ju Song, Byung-Koo Ahn*, and Jin-Ho Lee ${ }^{1}$ \\ Jeollabuk-do Agricultural Research and Extension Services, Iksan 570-704, Korea \\ ${ }^{I}$ Department of Bioenvironmental Chemistry, Chonbuk National University, Jeonju 561-756, Korea
}

(Received: May 20 2013, Accepted: May 27 2013)

This study was conducted to investigate the effects of boron treatments on flower spike dieback of Statice (Limonium spp.) grown in soilless hydroponic and soil cultures under rain shelter system. The growth of Statice was gradually improved with increasing boron applications in the hydroponics, but not in soil culture with boron treatment as foliar spray or soil application. The degree of flower spike dieback in 6 levels $(0$, no dieback incidence to 5 , very severe dieback incidence) ranged between 0.5 with boron application and 4.4 with no boron treatment. The content of boron in Statice flower spike increased with increasing rates of boron applications in the hydroponics, but the contents of $\mathrm{P}, \mathrm{Mg}$, and $\mathrm{N}$ were not affected by the boron application. However, K content was highest with no boron treatment. In soil culture, incidence of flower spike dieback decreased with foliar spray or soil application of boron. Therefore, boron application was effective in reducing flower spike dieback and improving cut-flower productivity and its quality, and the recommended rates of boron application were $50 \sim 80 \mathrm{ug} \mathrm{L}^{-1}$ for hydroponics culture whereas $0.2 \%$ borex or $\geq 0.4 \mathrm{~kg} \mathrm{10a}^{-1}$ boric acid by foliar spray application for soil culture.

Key words: Statice, Flower spike dieback, Boron, Hydroponic culture, Soil culture

Statice cut-flower quality and the degree of its flower spike dieback as affected by boron treatments in hydroponics system.

\begin{tabular}{|c|c|c|c|c|c|c|}
\hline \multirow{2}{*}{$\begin{array}{l}\text { Boron } \\
\text { treatment }\end{array}$} & \multirow{2}{*}{$\begin{array}{l}\text { Flowering } \\
\text { time }\end{array}$} & \multicolumn{3}{|c|}{ Flower spike } & \multirow{2}{*}{ Diameter } & \multirow{2}{*}{$\begin{array}{c}\text { Degree of } \\
\text { flower spike dieback }\end{array}$} \\
\hline & & Width & Length & Weight & & \\
\hline ug $L^{-1}$ & & --------- & ----------- & $\mathrm{g}$ & $\mathrm{mm}$ & $0 \sim 5^{\dagger}$ \\
\hline 0 & Aug. $19 \mathrm{a}^{\ddagger}$ & $32.2 \mathrm{~b}$ & $79.6 \mathrm{~b}$ & $39.0 \mathrm{c}$ & $3.7 \mathrm{c}$ & $4.4 \mathrm{a}$ \\
\hline 20 & Aug. 14 b & $44.6 \mathrm{a}$ & $106.2 \mathrm{a}$ & $53.4 \mathrm{~b}$ & $4.2 \mathrm{~b}$ & $2.6 \mathrm{~b}$ \\
\hline 50 & Aug. $13 \mathrm{~b}$ & $47.4 \mathrm{a}$ & $116.2 \mathrm{a}$ & $66.6 \mathrm{a}$ & $4.7 \mathrm{a}$ & $1.0 \mathrm{c}$ \\
\hline 80 & Aug. 12 b & $47.6 \mathrm{a}$ & $114.0 \mathrm{a}$ & $65.6 \mathrm{a}$ & $4.6 \mathrm{a}$ & $1.2 \mathrm{c}$ \\
\hline
\end{tabular}




\section{Introduction}

Statice는 갯질경이과 (Plumbaginaceae)의 Limonium속 초본식물로 원산지는 유럽, 중동, 아프리카, 남미, 중국, 시 베리아 등 비교적 널리 분포하고 있으며, 세계적으로는 약 200여종이 있다 (Bailey, 1978; Lee, 1993, Heywood, 1978). 우리나라에서 절화재배를 목적으로 일년생 스타티스 Limonium sinuata가 도입된 것은 1970 년대로 추정되고 있으며, 1980 년대 후반 절화소비가 증대되면서 Statice류가 주목을 받게 되었고, 1990년 이후에는 종간잡종 계열의 품종이 주류를 이루고 있다. 2011년 재배면적은 15.0 ha, 생산량은 530만 본이며, 생산액은 15 억원이었다 (MIFAFF, 2012). 주요 재배 지역은 전북, 충남, 경남, 경북, 전남 등이다. 재배면적은 2004년까지 $50 \mathrm{ha}$ 이상 유지되었으나 2005년부터 감소하는 추세를 보이고 있다.

일반적으로 Statice의 적정 토양 $\mathrm{pH}$ 는 $6.0 \sim 6.5$ 로 안개 초보다 낮은 수준이며, 양분 흡수 양상은 비슷하지만 칼슘 함량이 많은 알칼리성 토양을 좋아하는 안개초를 동일포장 에서 번갈아 재배함에 따라 Statice의 재배포장으로서 부적 당한 측면이 있다 (Miller, 1984). 식물은 칼슘과 붕소의 흡 수비가 일정범위에서 균형을 유지할 때에 정상적인 생육을 하고, 어떤 작물이든 붕소결핍상태가 심할수록 $\mathrm{Ca} / \mathrm{B}$ 비가 높아진다고 하였다 (Jones and Scarseth, 1944). 식물체중 석회함량이 적으면 붕소의 해독작용에 대한 저항력도 적으 며 석회 함량이 많으면 붕소 요구량도 많아진다. 즉 재배 연 수가 증가함에 따라 염류집적과 양분 불균형으로 작물 생육 이 불량해져 생산력 및 품질 저하를 초래하고 있다. 그리고 장마기에 고온과 낮은 일조 하에서 꽃대 늘어짐을 방지하기 위하여 극단적인 단수가 진행되어 Statice 화경이 목질화되 는 특성상 수분부족에 따른 양수분의 정상적인 흡수가 제한 받는 것도 하나의 원인으로 생각 할 수 있다.

붕소는 비금속 원소로서 토양 중에서는 $\mathrm{BO}_{3}{ }^{-3}$ 형태로 존 재하며, 토양의 총 붕소함량은 20 200 mg kg${ }^{-1}$ 이지만 식 물이 이용 가능한 양은 매우 적다. 유효범위는 $0.4 \sim 5.0 \mathrm{mg}$ $\mathrm{kg}^{-1}$ 으로 매우 좁으며, 이온화 되지 않는 성질 때문에 토 양으로부터 쉽게 용탈될 수 있다 (Hanson and Breen, 1985; Gupta, 1993). 붕소는 당과 전분 형성의 제어를 통해 증산 에 영향을 미치며, 세포발육과 신장, 탄수화물대사, 아미노 산형성, 오옥신대사, 그리고 단백질 합성에 중요한 역할을 한다 (Gupta, 1979a; Tisdale et al., 1985; Hirsch and Torrey, 1980; Funente et al., 1985). 식물생장에 있어서 꽃의 형성, 개화 및 결실, 발아와 화분관의 생장, 세포분열, 질소와 탄 소 및 펙틴의 대사, 가용성 염류의 흡수, 호르몬의 이동과 작용, 원형질막의 형성, 당류의 이동, 뿌리의 유관속 발달, 핵산 합성 등 주요 생리작용에 관여하는 것으로 알려져 있 다 (Davies, 1980; Ishida et al., 1988; Lotti et al., 1989;
Miller, 1984). 세포기관인 염색체, 리보좀 및 소포체 막에 다량의 붕소가 함유되어 있는데, 특히 세포벽에는 많은 양 의 붕소가 함유되어 있고 (Gilliam and Smith, 1980), 화훼 류 잎의 붕소함량과 화편의 붕소 함량을 보면 숙근류가 가 장 높고, 1,2 년생 초화류, 화목류, 구근류 순으로 낮은 경 향이었다 (Lee and Lee, 1997). 화훼류 가운데 해바라기나 카네이션 등이 붕소에 민감한 것으로 알려져 있다 (Adams et al., 1980; Mengel and Kirkby, 1987). 카네이션은 122.1 $\mathrm{mg} \mathrm{kg}{ }^{-1}$, 화편의 붕소함량은 아마릴리스 $4.0 \mathrm{mg} \mathrm{kg}^{-1}$, 군 자란 $53.3 \mathrm{mg} \mathrm{kg}^{-1}$, 카네이션 잎 $30 \sim 100 \mathrm{mg} \mathrm{kg}^{-1}$ 등 이었 다 (Hanson and Breen, 1988; Gupta, 1979b). Lee and Lee (1997)에 따르면 화훼류 붕소함량은 화판보다 잎에서 높고, 종에 따라 차이가 있다고 하였다.

일반적으로 붕소결핍은 전분과 당생성을 감소시키고 신 초생장과 발육을 저해하며, 칼슘과 칼륨 흡수, 증산 그리고 양분전류에 영향을 미친다. 증상은 초기에 신초생장이 없어 지고 어린잎과 정아가 검은색을 띠면서 괴사하고, 정아우세 성이 소실되어 심하게 맹아형성을 유도 (Tisdale et al., 1985), 통도조직 퇴화, 잎의 위축, 세포막 파괴와 갈변 괴사 현상 등이 나타난다 (Harada, 1982; Yamazaki, 1996). 또한 세포벽 구성물질인 pectin 형성이 불량하게 되고 정단 생장 이 정지되고 (Gupta, 1993), 많은 식물에서 불임현상 및 화 기의 기형화를 초래하고, 튤립의 경우 화색이 변하고, 목잘 림 현상이 나타나며, 화경이 짧아지고, 불규칙적으로 굽어 진다. 또한 잎과 화경의 고사가 빠르고, 구근 수량이 감소하 며, 외피 및 인편에 대형 괴사병반이 나타난다 (Gauch and Dugger, 1954; Pettinger). Hanson and Breen (1985)은 꽃 에 대한 붕소공급이 유관속조직, 특히 목부 발달에 의존한 다고 하였다.

붕소가 과다하면 초기에는 잎 선단이 황화되고 점차 잎 전체로 황화되면서 잎말림증상이 나타나고 괴사되는 속도 가 빠르고, 조기낙엽이 된다 (Francois, 1986; Gilliam and Smith, 1980; Jones et al., 1991). 그리고 잎에서 축적되지 는 않으나, 일반적으로 단자엽 식물은 잎 선단부에, 쌍자엽 식물은 잎 가장자리에 과잉증상이 잘 나타난다 (Francois, 1986).

절화 상품성을 떨어뜨리는 생리장해로 화경의 선단고사, 불개화지, 동해 등이 발생되고 있다. 절화 상품성에 피해를 주는 대표적인 증상은 화경의 선단고사이며, 증상은 꽃대의 최상부 가지가 말라 죽는다 (Photo 1). 화훼에서 선단고사가 발생된 가지는 갈색으로 변색되고, 소화의 발생이 적어 부 피감이 적어져 상품가치가 떨어지는 결과를 초래하고 있다 (Kang et al., 2009).

따라서 본 연구는 절화 상품성을 떨어뜨리는 Statice 화 경에 발생하는 선단고사에 대한 붕소 효과를 구명하기 위하 여 실시하였다. 


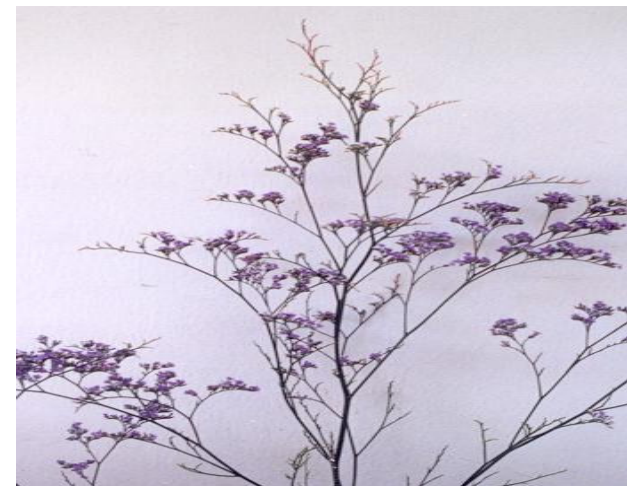

(A)

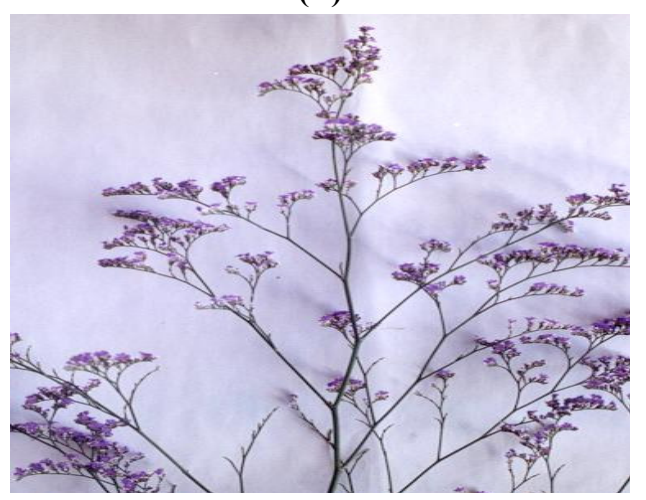

(B)

Photo 1. Flower spike dieback (A) of Limonium spp. 'Ocean Blue' and its normal condition (B)

\section{Materials and Methods}

품종 및 재배 전북 남원시 운봉읍에 위치한 전북농업 기술원 허브시험장 (해발 $500 \mathrm{~m}$ )의 단동형 비가림 하우스 포장에 숙근 Statice (Limonium spp.) 'Ocean Blue' 근삽묘 를 정식하여 실시하였다. 재배 및 포장관리는 숙근 Statice 의 일반재배법에 준하여 실시하였고, 생육 및 절화품질은 농촌진흥청 표준조사기준에 따라 조사하였다. 화경의 선단 고사 발생정도는 육안 식별에 따라 6단계로 구분하여 미발 생 0 , 극소 1 , 약간 2 , 보통 3 , 심함 4 , 극심 5 로 표기하였다.

붕소 처리 붕소 농도효과를 조사하기 위해 실시한 재 배형태는 양액재배용 성형 스티로폼 베드 $(\mathrm{W} 35 \times \mathrm{H} 20 \times \mathrm{L} 120$ $\mathrm{cm}$ )에 펄라이트 (1호)를 $10 \mathrm{~L}$ 정도 충진하고 4 월 10 일에 조 직배양묘를 $30 \times 40 \mathrm{~cm} 2$ 열로 처리구당 10 주씩 정식하였다. 양액은 Yamazaki액 $\left[\mathrm{Ca}\left(\mathrm{NO}_{3}\right)_{2} 4 \mathrm{H}_{2} \mathrm{O} 354.0 \mathrm{mg} \mathrm{L} \mathrm{L}^{-1}, \mathrm{KNO}_{3}\right.$
$336.5 \mathrm{mg} \mathrm{L}^{-1}, \mathrm{NH}_{4} \mathrm{NO}_{3} 54.0 \mathrm{mg} \mathrm{L}{ }^{-1}, \mathrm{Na}_{2} \mathrm{HPO}_{4} 12 \mathrm{H}_{2} \mathrm{O} 240.0$ $\mathrm{mg} \mathrm{L}^{-1}, \mathrm{Fe}$-EDTA $0.84 \mathrm{mg} \mathrm{L}{ }^{-1}, \mathrm{MgSO}_{4} 7 \mathrm{H}_{2} \mathrm{O} 247.0 \mathrm{mg} \mathrm{L}{ }^{-1}$, $\mathrm{KOH} 240.0 \mathrm{mg} \mathrm{L}^{-1}, \mathrm{MnSO}_{4} 4 \mathrm{H}_{2} \mathrm{O} 0.55 \mathrm{mg} \mathrm{L}^{-1}, \mathrm{CuSO}_{4} 5 \mathrm{H}_{2} \mathrm{O}$ $0.05 \mathrm{mg} \mathrm{L}^{-1}, \mathrm{ZnSO}_{4} 7 \mathrm{H}_{2} \mathrm{O} 0.33 \mathrm{mg} \mathrm{L}{ }^{-1}, \mathrm{Na}_{2} \mathrm{MoO}_{4} 2 \mathrm{H}_{2} \mathrm{O} 0.05$ $\mathrm{mg} \mathrm{L} \mathrm{L}^{-1}$ 을 기본으로 하고 $\mathrm{H}_{3} \mathrm{BO}_{3}$ (99.5\%, SAMCHUN, Korea)를 사용하여 붕소 농도를 $0,20,50,80 \mathrm{ug} \mathrm{L}{ }^{-1}$ 로 처 리하였으며, 양액 공급량은 1 일에 포기당 $400 \mathrm{~mL}$ 이며, 오 전 10 시와 오후 5 시경 포기당 $200 \mathrm{~mL}$ 씩 2회 공급하였다.

붕소의 토양처리와 엽면시비 효과에 따른 Statice의 생육 및 선단고사 정도를 구명하기 위하여 Statice 조직배양묘를 4 월 10 일에 재식밀도 $30 \times 40 \mathrm{~cm}, 2$ 열로 처리구당 10 주씩 정 식하였고, 처리구는 난괴법 3 반복으로 배치하였다. 조사기 간 동안 (6월 하순 9월 하순) 하우스 내 최고 온도는 30 $37^{\circ} \mathrm{C}$ 로 $40^{\circ} \mathrm{C}$ 이하, 최저 온도는 $15 \sim 25^{\circ} \mathrm{C}$ 범위에서 주로 $20^{\circ} \mathrm{C}$ 수준으로 유지하였으며, 재배한 토양의 물리화학적 특성은 Table 1에 나타나 있다. 붕소의 토양처리 효과는 $\mathrm{H}_{3} \mathrm{BO}_{3}$ 를 사용하여 무처리한 것을 대조구로 하고, $0.2,0.4,0.8 \mathrm{~kg}$ $10 \mathrm{a}^{-1}$ 을 경운 전에 토양 살포하였다. 붕소 토양처리에 따른 잎과 토양의 붕소함량 조사는 8월 14 일에 채취하여 실시하 였다. 붕소의 엽면시비 효과는 $0.2 \% \mathrm{Na}_{2} \mathrm{~B}_{4} \mathrm{O}_{7} \cdot 10 \mathrm{H}_{2} \mathrm{O}$ 를 무처 리, 정식 후 60 일에 1 회 처리, 2 회는 120 일에 포기당 $10 \mathrm{~mL}$ 씩 맑은 날 오전 엽면에 분무살포 하였다. 붕소처리에 따른 잎과 토양의 붕소함량 조사는 8월 14 일에 시료를 채취하여 실시하였다.

토양 및 식물체 분석 채취한 토양은 실험실에서 풍건 하고 $2 \mathrm{~mm}$ 체를 통과한 것을 농업과학기술원 토양 및 식물 체 분석법 (NIAST, 2010)에 준하여 실시하였다. 토양 $\mathrm{pH}$ 와 $\mathrm{EC}$ 는 풍건토양과 증류수를 $1: 5(\mathrm{w} / \mathrm{v})$ 비율로 하여 $\mathrm{pH}$ Meter (EUTECH COND600)와 EC Meter (EUTECH ECOSCAN)로 각각 측정하였고, 유기물은 Tyurin법, 유효인산은 Lancaster 법, 치환성양이온은 $1 \mathrm{~N} \mathrm{CH}_{3} \mathrm{COONH}_{4}$ ( $\mathrm{pH}$ 7.0)으로 치환 추 출하여 원자흡광분광광도계 ( $\mathrm{GBC}$, Avanta, Australia)를 이용하여 분석하였다. 토양중 유효붕소함량은 토양 $10 \mathrm{~g}$ 에 증류수 $20 \mathrm{~mL}$ 를 가한 후 전열판 위에서 정확히 5 분간 끓인 후 No. 2 여지로 여과하여 여액 $1 \mathrm{~mL}$ 를 $100 \mathrm{~mL}$ 플라스틱 비이커에 취하고 curcumin 수산용액을 $4 \mathrm{~mL}$ 를 넣어 $55 \pm$ $3^{\circ} \mathrm{C}$ 수조 위에서 완전히 건고시킨 후 $95 \% \mathrm{C}_{2} \mathrm{H}_{5} \mathrm{OH} 25 \mathrm{~mL}$ 로 용해하고 No. 2 여지로 여과하여 UV/VIS spectrophotometer (Shimadzu UV-1201)로 파장 $540 \mathrm{~nm}$ 에서 측정하였다.

Table 1. Selected physical and chemical properties of soil in the experimental field.

\begin{tabular}{|c|c|c|c|c|c|c|c|c|c|c|}
\hline \multirow{2}{*}{ Soil texture } & \multirow{2}{*}{$\mathrm{pH}$} & \multirow{2}{*}{$\mathrm{EC}$} & \multirow{2}{*}{$\mathrm{OM}$} & \multirow{2}{*}{ Avail. $\mathrm{P}_{2} \mathrm{O}_{5}$} & \multicolumn{4}{|c|}{ Exch. cations } & \multirow{2}{*}{$\mathrm{T}-\mathrm{N}$} & \multirow{2}{*}{$\mathrm{B}$} \\
\hline & & & & & $\mathrm{K}$ & $\mathrm{Ca}$ & $\mathrm{Mg}$ & $\mathrm{Na}$ & & \\
\hline & $(1: 5)$ & $\mathrm{dS} \mathrm{m}^{-1}$ & $\mathrm{~g} \mathrm{~kg}^{-1}$ & $\mathrm{mg} \mathrm{kg}{ }^{-1}$ & \multicolumn{4}{|c|}{----- $\mathrm{cmol}_{\mathrm{c}} \mathrm{kg}^{-1}$} & ---- $\mathrm{m}$ & --- \\
\hline Sandy loam & 7.0 & 0.73 & 33.5 & 768 & 0.75 & 6.60 & 1.88 & 0.09 & 112.0 & 0.82 \\
\hline
\end{tabular}


식물체 분석은 시료를 열풍건조기에서 $60 \sim 80^{\circ} \mathrm{C}$ 로 72 시 간 건조한 후 분쇄한 시료를 $\mathrm{H}_{2} \mathrm{SO}_{4}-\mathrm{H}_{2} \mathrm{O}_{2}$ 혼합액으로 분해 하여 T-N는 Kjeldahl 분해·증류장치 (FOSS, Kjeltec Auto Distillation)를 사용하여 측정하였고, 인산은 ammonium vanadate법에 의한 비색정량, 무기물은 습식분해액을 증류 수로 희석하여 유도결합플라즈마분광광도계 (GBC, Integra, Australia)로 측정하였다. 붕소정량은 curcumin법으로 분석 하였는데, 시료 $0.2 \mathrm{~g}$ 에 $0.5 \mathrm{~N}-\mathrm{HCl} 10 \mathrm{~mL}$ 를 가하여 2시간 진탕 후 $3,000 \mathrm{rpm}$ 에서 15 분간 원심분리하고 여과된 여액 을 curcumin 용액으로 발색시켜 파장 $540 \mathrm{~nm}$ 에서 비색정 량 (Shimadzu UV-1201) 하였다.

통계분석방법 분석한 자료의 통계적인 분석은 SPSS (12.0K)를 사용하여 Duncan 검정을 실시하였다.

\section{Results and Discussion}

붕소 농도의 영향 Statice 선단고사에 대한 붕소 효과 를 검토하기 위해 스티로폼 베드에 양액재배한 Statice를 정식 3개월 후인 7월 14일경에 생육상황을 조사하였다 (Table 2). 붕소 처리량이 증가할수록 엽장, 엽폭, 엽수, 초 장 등이 향상되는 경향이 나타났으나, 무처리나 $20 \mathrm{ug} \mathrm{L}^{-1}$ 처리수준에서는 차이가 없었다. Shear and Faust (1980)에
따르면 식물생장은 2 가지 영양의 요건, 즉 성분요소 농도와 성분요소간의 균형에 의하여 지배된다고 하였는데, 붕소 농 도가 높을수록 초장, 엽장, 엽수, 초폭 등에서 양호한 결과 를 보였다.

붕소농도가 높을수록 Statice 개화기는 빨라지는 경향을 보였는데 (Table 3), 붕소 $80 \mathrm{ug} \mathrm{L}^{-1}$ 처리구의 경우 무처리 구에 비하여 7 일 정도 빨랐다. 절화품질에 있어 화수폭, 절 화장 등은 50 과 $80 \mathrm{ug} \mathrm{B} \mathrm{L}{ }^{-1}$ 처리구에서 양호하였고, 무처 리구에서 절화품질이 극히 낮은 수준을 보였다.

선단고사 정도는 50 과 $80 \mathrm{ug} \mathrm{B} \mathrm{L}{ }^{-1}$ 처리구에서 $1.0 \sim 1.2$ 로 같은 수준을 보였고, 무처리구에서는 4.4 로 가장 심하게 나타났다. Arthur (1953)는 붕소가 결핍되면 세포가 갈변하 고 코르크화 되는데, 이것은 세포내에서 polyphenol oxidase 의 역가가 강화되어 phenol계 화합물이 산화되기 때문이라 고 하였으며, 줄기와 상부의 갈변고사 및 줄기와 뿌리가 부 분적으로 파열되고 흑변 한다고 하였다. 콩과식물의 경우 붕소를 공급하지 않으면 생장이 나빠지고 흑색의 반점이 생 기며, 자당은 붕소가 존재함으로써 잎에서 다른 부위로 이 행이 촉진되고, lignin형성, RNA대사, IAA의 간접적 억제, glucose 대사계의 아주 복잡한 요인들에 의해 지배된다고 하였다 (Alina and Henryk, 1985; Lotti et al., 1989).

Choi et al. (1986)은 배나무 사경 재배 시 배양액의 붕소 농도가 높을수록 엽내 $\mathrm{K}$ 함량은 감소하고, $\mathrm{P}$ 함량은 증가하

Table 2. Effect of boron treatment on the growth conditions of Statice determined at 90 days after planting in hydroponics system.

\begin{tabular}{|c|c|c|c|c|}
\hline \multirow{2}{*}{ Boron treatment } & \multicolumn{2}{|c|}{ Leaf } & \multirow{2}{*}{ No. of leaves } & \multirow{2}{*}{ Plant width } \\
\hline & Length & Width & & \\
\hline ug $\mathrm{L}^{-1}$ & \multicolumn{2}{|c|}{-------- cm ------ } & & $\mathrm{cm}$ \\
\hline 0 & $8.0 \mathrm{~b}^{\dagger}$ & $2.9 \mathrm{~b}$ & $26.5 \mathrm{c}$ & $15.3 \mathrm{c}$ \\
\hline 20 & $8.0 \mathrm{~b}$ & $3.2 \mathrm{~b}$ & $27.6 \mathrm{~b}$ & $15.4 \mathrm{c}$ \\
\hline 50 & $8.9 \mathrm{a}$ & $3.6 \mathrm{~b}$ & $28.0 \mathrm{~b}$ & $16.1 \mathrm{~b}$ \\
\hline 80 & $9.0 \mathrm{a}$ & $4.3 \mathrm{a}$ & $29.5 \mathrm{a}$ & $17.3 \mathrm{a}$ \\
\hline
\end{tabular}

${ }^{\dagger}$ Numbers followed by the same letter with a column are not significantly different (Duncan test, $p<0.05$ ).

Table 3. Statice cut-flower quality and the degree of its flower spike dieback as affected by boron treatments in hydroponics system.

\begin{tabular}{|c|c|c|c|c|c|c|}
\hline \multirow{2}{*}{$\begin{array}{l}\text { Boron } \\
\text { treatment }\end{array}$} & \multirow{2}{*}{$\begin{array}{l}\text { Flowering } \\
\text { time }\end{array}$} & \multicolumn{3}{|c|}{ Flower spike } & \multirow{2}{*}{ Diameter } & \multirow{2}{*}{$\begin{array}{c}\text { Degree of } \\
\text { flower spike dieback }\end{array}$} \\
\hline & & Width & Length & Weight & & \\
\hline ug $\mathrm{L}^{-1}$ & & \multicolumn{2}{|c|}{ - } & $\mathrm{g}$ & $\mathrm{mm}$ & $0 \sim 5^{\dagger}$ \\
\hline 0 & Aug. $19 \mathrm{a}^{\ddagger}$ & $32.2 \mathrm{~b}$ & $79.6 \mathrm{~b}$ & $39.0 \mathrm{c}$ & $3.7 \mathrm{c}$ & $4.4 \mathrm{a}$ \\
\hline 20 & Aug. 14 b & $44.6 \mathrm{a}$ & $106.2 \mathrm{a}$ & $53.4 \mathrm{~b}$ & $4.2 \mathrm{~b}$ & $2.6 \mathrm{~b}$ \\
\hline 50 & Aug. $13 \mathrm{~b}$ & $47.4 \mathrm{a}$ & $116.2 \mathrm{a}$ & $66.6 \mathrm{a}$ & $4.7 \mathrm{a}$ & $1.0 \mathrm{c}$ \\
\hline 80 & Aug. $12 \mathrm{~b}$ & $47.6 \mathrm{a}$ & $114.0 \mathrm{a}$ & $65.6 \mathrm{a}$ & $4.6 \mathrm{a}$ & $1.2 \mathrm{c}$ \\
\hline
\end{tabular}

${ }^{\dagger} 0$, no dieback incidence ; 1, very low dieback incidence; 2, slight dieback incidence; 3, intermediate dieback incidence; 4 , severe dieback incidence; 5 , very severe dieback incidence.

${ }^{\ddagger}$ Numbers followed by the same letter with a column are not significantly different (Duncan test, $p<0.05$ ). 
였으며, $\mathrm{N}, \mathrm{Ca}$ 및 $\mathrm{Mg}$ 함량은 차이가 없었다고 하였다. 그러 나 붕소 $50 \mathrm{ug} \mathrm{L}^{-1}$ 처리구에서 Statice 화경의 붕소함량이 $61.5 \mathrm{mg} \mathrm{kg}^{-1}$ 으로 가장 많이 흡수되었고, $\mathrm{P}, \mathrm{Mg}, \mathrm{N}$ 의 경우 붕소의 처리량에 관계없이 비슷한 수준을 보였다 (Table 4). 그러나 $\mathrm{K}$ 는 무처리구에서 $6.17 \%$ 로 높은 경향을 보였다. Gilliam and Watson (1981)은 주목의 신초에서 붕소의 농도 가 증가함에 따라 $\mathrm{Ca}$ 은 감소되어서 길항관계가 나타났음을 보고하였으나, 본 실험에서는 무처리에 비해 높았지만, 붕 소의 처리량에 따른 유의성은 나타나지 않았다.

붕소 엽면시비 효과 붕소 엽면시비구에서는 무처리구 와 비교할 때 Statice의 생육이 향상되었으나, 붕소의 엽면 처리 횟수에 관계없이 비슷한 생육 결과를 나타내었다 (Data not shown), 엽면처리 횟수에 따른 절화품질은 비슷 한 경향을 보였고, 절화중은 화경당 $100 \mathrm{~g}$ 이상으로 유의성 이 나타나지 않았다.

절화량은 통계적인 유의성은 없었지만 평균값은 무처리 <1회<2회 순이었다. 선단고사율은 무처리에서 가장 많았고 붕소를 엽면시비할 경우 $0.5 \sim 0.8 \%$ 수준이었다 (Table 5). Azuma (1984)은 L. sinuata 화경의 붕소 함유량은 정상엽 에서 $6.8 \sim 8.0 \mathrm{mg} \mathrm{kg}^{-1}$ 인 반면, 장해엽에서는 $3.2 \sim 5.6 \mathrm{mg}$ $\mathrm{kg}^{-1}$ 으로 낮다고 하였으며, 붕소 $0.5 \%$ 용액을 엽면 살포하 면 어느 정도 방지 할 수 있다고 하였다. 그러나 Lee and Lee (1997)에 의하면 Statice 원종인 L. caspium Gams의 붕 소 함량은 화편에서 $14.0 \mathrm{mg} \mathrm{kg}^{-1}$, 잎은 $21.1 \mathrm{mg} \mathrm{kg}^{-1}$ 이며,
L. dumosum Mill은 화편에서 $22.5 \mathrm{mg} \mathrm{kg}^{-1}$, 잎은 $33.1 \mathrm{mg}$ $\mathrm{kg}^{-1}$ 이었다고 밝혀 붕소 함유량은 일년생보다 높은 결과를 보였다.

Statice 정식 약 4 개월 후에 조사한 붕소 엽면시비 횟수 에 따른 잎과 토양의 붕소 함량은 무처리에 비하여 처리횟 수와 비례관계를 보였다. 토양 중 붕소 함량은 정식 전 0.82 $\mathrm{mg} \mathrm{kg}^{-1}$ (Table 2)이었으나 무처리구에서는 정식 전 함량의 약 $50 \%$ 감소하였고, 2 회 처리할 경우 정식 전 수준의 함량 으로 증가하였다.

붕소의 토양처리 효과 붕소의 토양처리에 따른 Statice 의 생육 및 절화품질은 $\mathrm{H}_{3} \mathrm{BO}_{3} \quad 0.2 \sim 0.8 \mathrm{~kg} \mathrm{laa}^{-1}$ 의 처리량 차이에 따라 통계적 유의성이 나타나지 않았다 (Data not shown). 이러한 결과는 토양처리량이 상대적으로 낮아 토 양 중 붕소의 유효함량은 다소 증가하는 경향을 보였고, Statice 잎의 흡수량은 붕소 처리량의 증가에 따라 증가하 였으나 (Table 6) 생육에는 뚜렷하게 영향을 주지 못한 것으 로 보여진다.

그러나 토양 중 $\mathrm{H}_{3} \mathrm{BO}_{3}$ 를 $0.4 \mathrm{~kg}_{10 \mathrm{a}^{-1}}$ 수준으로 처리한 구에서 선단고사율이 가장 낮았으며, 0.2 와 $0.8 \mathrm{~kg} 10 \mathrm{a}^{-1}$ 처 리구에서는 같은 수준을 보였고, 무처리에서는 $4.4 \%$ 로 가 장 높았다. 절화량은 통계적인 유의성은 없었으나 평균값으 로 비교해 보면 붕소 처리량과 비례관계였고, 절화품질도 높아지는 경향을 보였다.

L. sinuata는 재배과정에서 꽃대 날개에 균열이 생겨 거

Table 4. Nutrient contents in flower spike of Statice as influenced by boron treatments in hydroponic culture.

\begin{tabular}{|c|c|c|c|c|c|c|}
\hline $\begin{array}{l}\text { Boron } \\
\text { treatment }\end{array}$ & B & $\mathrm{P}$ & $\mathrm{Ca}$ & $\mathrm{Mg}$ & $\mathrm{K}$ & $\mathrm{N}$ \\
\hline ug $L^{-1}$ & $\mathrm{mg} \mathrm{kg}^{-1}$ & -----.. & ------- & $\%-$ & 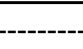 & ------ \\
\hline 0 & 30.8 & 0.17 & 0.18 & 0.69 & 6.17 & 2.58 \\
\hline 20 & 53.4 & 0.19 & 0.27 & 0.71 & 5.32 & 2.59 \\
\hline 50 & 61.5 & 0.18 & 0.23 & 0.73 & 5.03 & 2.25 \\
\hline 80 & 60.5 & 0.19 & 0.25 & 0.71 & 5.18 & 2.74 \\
\hline
\end{tabular}

Table 5. Statice cut-flower quality, the degree of its flower spike dieback, and boron contents in the plant leaf and soil as affected by foliar spray applications of boron in soil culture system.

\begin{tabular}{|c|c|c|c|c|c|}
\hline \multirow{2}{*}{ Treatment } & \multirow{2}{*}{$\begin{array}{l}\text { Total yield of } \\
\text { cut-flower }\end{array}$} & \multirow{2}{*}{$\begin{array}{c}\text { Incidence of flower spike } \\
\text { dieback }\end{array}$} & \multirow{2}{*}{$\begin{array}{c}\text { Degree of } \\
\text { flower spike dieback }\end{array}$} & \multicolumn{2}{|c|}{ Boron content } \\
\hline & & & & Leaf & Soil \\
\hline & ---------- & lles $10 a^{-1}$ & $(0 \sim 5)^{\dagger}$ & - & ---------- \\
\hline Control & $3,310 \mathrm{a}^{\ddagger}$ & $146 \mathrm{a}$ & $4.4 \mathrm{a}$ & $49.5 \mathrm{c}$ & $0.49 \mathrm{~b}$ \\
\hline $1 \mathrm{st}$ & 3,435 a & $27 \mathrm{~b}$ & $0.8 \mathrm{~b}$ & $57.4 \mathrm{~b}$ & $0.77 \mathrm{a}$ \\
\hline 2nd & $3,462 \mathrm{a}$ & $15 \mathrm{~b}$ & $0.5 \mathrm{~b}$ & $71.2 \mathrm{a}$ & $0.81 \mathrm{a}$ \\
\hline
\end{tabular}

${ }^{\dagger} 0$, no dieback incidence ; 1, very low dieback incidence; 2, slight dieback incidence; 3, intermediate dieback incidence; 4, severe dieback incidence; 5 , very severe dieback incidence.

${ }^{\ddagger}$ Numbers followed by the same letter with a column are not significantly different (Duncan test, $\mathrm{p}<0.05$ ). 
Table 6. Statice cut-flower quality, the degree of its flower spike dieback, and boron contents in the plant leaf and soil as affected by boron treatments in soil.

\begin{tabular}{|c|c|c|c|c|c|}
\hline \multirow{2}{*}{ Treatment } & \multirow{2}{*}{$\begin{array}{l}\text { Total yield of } \\
\text { cut-flower }\end{array}$} & \multirow{2}{*}{$\begin{array}{c}\text { Incidence of flower spike } \\
\text { dieback }\end{array}$} & \multirow{2}{*}{$\begin{array}{c}\text { Degree of } \\
\text { flower spike dieback }\end{array}$} & \multicolumn{2}{|c|}{ Boron content } \\
\hline & & & & Leaf & Soil \\
\hline $\operatorname{kg} 10 \mathrm{a}^{-1}$ & -------------- b & lles $10 \mathrm{a}^{-1}$ & $(0 \sim 5)^{\dagger}$ & \multicolumn{2}{|c|}{---- $\mathrm{mg} \mathrm{kg}^{-1}$} \\
\hline Control & $3,310 \mathrm{a}^{\ddagger}$ & $146 \mathrm{a}$ & $4.4 \mathrm{a}$ & $49.5 \mathrm{c}^{\dagger}$ & $0.49 \mathrm{~d}$ \\
\hline 0.2 & $3,382 \mathrm{a}$ & $37 \mathrm{~b}$ & $1.1 \mathrm{~b}$ & $51.4 \mathrm{~b}$ & $1.24 \mathrm{c}$ \\
\hline 0.4 & 3,433 a & $20 \mathrm{c}$ & $0.6 \mathrm{c}$ & $51.5 \mathrm{~b}$ & $2.35 \mathrm{~b}$ \\
\hline 0.8 & 3,387 a & $37 \mathrm{~b}$ & $1.1 \mathrm{~b}$ & $56.5 \mathrm{a}$ & $4.31 \mathrm{a}$ \\
\hline
\end{tabular}

${ }^{\dagger} 0$, no dieback incidence ; 1, very low dieback incidence; 2, slight dieback incidence; 3, intermediate dieback incidence; 4, severe dieback incidence; 5 , very severe dieback incidence.

${ }^{\ddagger}$ Numbers followed by the same letter with a column are not significantly different (Duncan test, $\mathrm{p}<0.05$ ).

치상으로 되는 경우가 있는데, 화경에 붙어 있는 날개상의 주름이 갈색이 되고 옆으로 갈라지는 장해에 대해서 Azuma (1984)은 붕소의 결핍증으로 보고하였다. Ubukata (1987)은 토양 $\mathrm{pH}$ 가 지나치게 높아지지 않도록 하고, 급격한 온도 변 화를 줄여 식물체에 스트레스를 주지 않도록 하면 예방 효 과가 있으며, 본 장해의 발생은 $\mathrm{H}_{3} \mathrm{BO}_{3} 400 \mathrm{~g}^{10 \mathrm{a}^{-1}}$ 의 시용 으로 예방 할 수 있다고 하였다.

Ganch and Dugger (1953)에 따르면 일반적으로 식물이 이용 가능한 토양 중 붕소는 열수가용성형태로 $0.4 \sim 0.5$ $\mathrm{mg} \mathrm{kg}^{-1}$ 범위이며, $0.4 \mathrm{mg} \mathrm{kg}^{-1}$ 이하의 농도에서는 결핍증 상을 보이고, $7.0 \mathrm{mg} \mathrm{kg}^{-1}$ 이상에서는 과잉장해 증상을 보 인다고 하였으나, 본 연구의 Statice 재배지 토양의 붕소함 량은 $1.2 \sim 4.3 \mathrm{mg} \mathrm{kg}^{-1}$ 로 적정수준을 보였다. 그러나 토양 처리 수준 내의붕소가 Statice 생장과 절화품질에 뚜렷한 영향을 미치지는 않았으나, 화경의 선단고사는 붕소의 토양 처리에 따라 감소하였고 절화량과 절화품질을 향상시켰다. 그러므로 Statice 재배 시 붕소 엽면시비를 2 회 정도 실시하 거나, $\mathrm{H}_{3} \mathrm{BO}_{3}$ 를 $0.4 \mathrm{~kg} \mathrm{l}_{10 \mathrm{a}}^{-1}$ 이상의 수준으로 토양처리 하 도록 제시할 수 있다고 판단된다.

\section{Conclusion}

숙근 Statice (Limonium spp.) 'Ocean Blue'의 화경 (flower spike)에 발생하는 선단고사 (dieback) 원인과 대책 을 구명하기 위해 비가림하우스 (rain-sheltered culture or rainfall shelter)에서 양액재배 (hydroponic culture)와 토 양재배 (soil culture)를 통해 붕소 공급효과를 검토하였다. Statice 생육은 양액재배에서 붕소 처리량이 증가할수록 향 상되는 경향을 나타내었으나, 엽면시비나 토양처리 시에는 나타나지 않았다. 붕소를 처리하였을 때 선단고사 정도는 6 단계 (6 levels: 0, no dieback incidence to 5, very severe dieback incidence) 중 가장 낮은 0.5 부터, 붕소 무처리구인
4.4까지 분포하였다. 양액재배 시 Statice 화경의 붕소함량 은 붕소처리량에 따라 증가하였고, $\mathrm{P}, \mathrm{Mg}, \mathrm{N}$ 는 차이가 없 었지만 $\mathrm{K}$ 는 무처리구에서 가장 높았다.

붕소를 엽면시비 (foliar application)를 할 경우 선단고사 는 크게 감소하였고, 토양과 잎의 붕소함량은 붕소 처리량 에 비례하여 증가 하였다. 붕소 토양처리량에 따른 Statcie 생육과 절화품질 (cut-flower) 사이에는 유의성이 나타나지 않았으나, 선단고사는 $\mathrm{H}_{3} \mathrm{BO}_{3} 0.4 \mathrm{~kg}_{10 a^{-1}}$ 의 처리 수준에서 가장 낮았고, 붕소처리량의 증가에 따라 절화량, 절화품질, 토양과 잎의 붕소함량이 증가하는 경향을 보였다.

따라서 Statice 양액재배 시 붕소를 50 $80 \mathrm{ug} \mathrm{L}^{-1}$ 수준으 로 처리하거나, 토양재배 시 $0.2 \% \mathrm{Na}_{2} \mathrm{~B}_{4} \mathrm{O}_{7} \cdot 10 \mathrm{H}_{2} \mathrm{O}$ 를 2 회 정 도 엽면시비 또는 $\mathrm{H}_{3} \mathrm{BO}_{3}$ 을 $0.4 \mathrm{~kg} \mathrm{10a}^{-1}$ 수준 이상으로 토 양에 처리한다면 선단고사를 감소시켜 절화량과 품질을 향 상시킬 수 있다고 판단된다.

\section{References}

Adams, P., G.J. Graves, and G. W. Winsor. 1980. Some effects of micro-nutrients and liming on the production and quality of glasshouse carnations grown in quality of glasshouse carnations grown in a peat-sand substrate. J. Hort. Sci. 55(2):89-96.

Alina, K.P. and P. Henryk. 1985. Trace element in soils and plants. pp. 129-135. CRC press, Inc. Boca Raton.

Arthur, Prince. 1953. Boron important to crops. Better crops with plant food.

Azuma. 1984. Study of statice(Limonium sinuatum Mill.) on forcing culture(Vol.1), photoperiod response and flower wings split phenomenon. Kochi Horticultural experiment station. 2:45-50

Bailey, L.H. 1978. Hortus third. MaCmillan, New York.

Choi, J.S., J.C. Lee, S.B. Kim, and J.Y. Moon. 1986. Studies on cause of shoot dieback in Pear Trees. J. Kor. Soc. Hort. Sci. 27(2):149-156. 
Davies, B.E. 1980. Applied soil trace elements. pp. 55-176. John Wiley \& Sons, New York.

Francois, L.E. 1986. Effect of excess boron on broccoli, cauliflower and radish. J. Amer. Soc. Hort. Sci. 111(4):494-498.

Gauch. H.G. and W.M. Dugger. 1953. The role of boron on the translocation of sucrose. Plant Physiol. 28: 457-487.

Gilliam, C.H. and E.M. Smith. 1980. Sources and symptoms of boron toxicity in container grown woody ornamentals. J. Arboriculture. 6(8):209-212.

Gilliam, C.H. and M.E. Watson. 1981. Boron accumulation in Taxis media. Hort. Science. 16(3):340-341.

Gupta. U.C. 1979a. Boron and its role in crop production. pp. 87-155. CRC Press. London.

Gupta, U.C. 1979b. Boron nutrition of crops. Adv. Agron. 31:273-303.

Gupta, U.C. 1993. Boron molybdenum and selenium status in different plant parts in forage legumes and vegetable crops. J. Plant Nutr. 14:613.

Hanson, E.J. and P.J. Breen. 1985. Xylem differentiation and boron accumulation in 'Italian' prune flower buds. J. Amer. Soc. Hort. Sci. 111:566-570.

Hanson, E.J. and P.J. Breen. 1988. Xylem differentiation and boron accumulation in 'Italian' prune flower buds. J. Amer. Soc. Hort. Sci. 111:566-570.

Harada. 1982. Plant life and micro-elements. Association of Agricultural fishing culture. 88-132. Tokyo.

Heywood, V.H. 1978. Flowering plants of the world. Oxford Univ. Press. London.

Hirsch, A.M. and J.G. Torrey. 1980. Ultrastructural changes in sunflower root cells in relation to boron deficiency and added auxin. Can. J. Bot. 58:856-866.

Ishida, A., A. Nukaya, and H. Shigeoka. 1988. Effect of applied concentrations of boron and calcium on growth, vase life and leaf marignal burn in chrysanthemums. J. Japan Soc. Hort. Sci. 57(2):273-278.

Jones, H.E. and G.D. Scarseth. 1944. The calcium-boron balance in plants as related to boron needs. Soil. Sci. $57: 15-24$
Jones, J.B., J.B. Wol, and H.A. Mills. 1991. Plant analysis handbook. pp. 13, 75-76. Micro-Macro Publishing, Inc. Georgia.

Kang, M.H., D.C. Cheong, C.H. Choi, H.C. Lim, Y.J. Song, T.H. Noh, D.K. Lee, and H.M. Kim. 2009. First report of stem rot in statice caused by Rhizoctonia solani in Korea. Res. Plant Dis. 15(1):54-56.

Lee, K.H. and J.S. Lee. 1997. Boron content distribution of leaves, petals, and soils in floricultural crops. J. Kor. Soc. Hort. Sci. 38(5):561-568.

Lee, T.B. 1993. Illustrated flora of Korea. Hangmunsa. Seoul. Lotti, G., A. Savoizzi, and S. Balzini. 1989. Distribution of boron and principal mineral elements in flowers in relation to the content in leaves. Agrochimica. 33:129-142.

Mengel, K. and E.A. Kirkby. 1987. Principle of plant nuitrition. pp. 559-572. International Potash Institute. Switzerland.

Miller, P.J. 1984. Disease symptoms in tulips due to boron deficiency. Vakblad voor de Bloemisterij 39(34):42-43.

MIFAFF (Ministry for Food, Agriculture, Forestry and Fisheries). 2012 Statistics for floricultural industry in 2011. MIFAFF, Gwacheon, Korea.

NIAST. 2010. Method of soil and plant analysis. National Institute of Agricultural Science and Technology, Suwon, Korea.

Pettinger, N.A. 1932. Some nutritional disorders in corn grown in sand cultures. Phytopathology 22:33-51.

Shear, C.B. and M. Faust. 1980. Nutritional range in deciduous tree fruit and nuts. Hort. Rev. 2:145-151. AVI Publishing Co. Westport, Connecticut, USA

Tisdale, S.L., W.L. Nelson, and J. D. Beaton. 1985. Soil fertility and fertilizers, 4th ed. MacMillan, New York.

Ubukata. 1987. Study of fertilization management of cold-season flower(Vol.1). Hokkaido Agricultural experiment station. 54:30-41

Yamazaki. 1996. Micro-element and macro-element. Bakusa. Tokyo. 239-262. 